\title{
Chick embryo inoculation as a pathogenicity test for Candida species
}

\author{
BETTY M. PARTRIDGE, M. A. ATHAR, AND H. I. WINNER \\ From the Microbiology Department, Charing Cross Hospital Medical School, London
}

SYNOPSIS The lesions produced by six Candida species on the chorioallantoic membrane (CAM) of the developing chick are described and compared. It is suggested that CAM inoculation be used as a pathogenicity test for Candida species.

Members of the genus Candida normally occur as human commensals. Serious clinical infections with these organisms appear to be increasing owing to sophisticated modern therapy such as antibiotics and immunosuppression. Among clinicians there is a growing appreciation of the possible pathogenic role of Candida species, and clinical pathologists are asked with increasing frequency to assess the pathogenicity of isolated candidas.

The rabbit, rat, guinea pig, and mouse are all susceptible to Candida albicans, and the pathogenicity of a culture can readily be determined by intravenous injection into one of these animals (Winner and Hurley, 1964). The use of mature animals, however, has obvious drawbacks.

We have found CAM inoculation to be a simple, convenient, and inexpensive method of determining pathogenicity. One of its advantages is that it is widely used in virus and other microbial infections and the embryology and pathology of the developing chick are well understood. It is a logical choice for another important reason-Candida species are natural pathogens of chicks and other birds (Jungherr, 1933; Hinshaw, 1934; Jungherr, 1934; Salisbury, 1949).

\section{Historical}

Moore (1941) studied the effect of a wide range of pathogenic fungi, including Candida albicans, on chick embryos. Meyer and Ordal (1946) found that C. albicans and C. stellatoidea produced severe lesions on the CAM and embryo death. Other Candidas produced milder or no lesions. Norris, Shorey, and Bongiovanni (1948) compared the effects of intravenous, amniotic, and CAM inocu-

Received for publication 3 February 1971. lation, using both living and killed suspensions of C. albicans Killed suspensions did not produce any lesions; living suspensions produced granulomatous lesions of the CAM after direct inoculation.

These studies indicated that chick embryo culture could be used as a pathogenicity test for Candida species as it had already been used for dermatophytes (Partridge, 1965) and coccidioides (Roessler, Converse, and Geating, 1961).

In the present study, CAM inoculation was preferred because the lesions are visible, and the membrane can easily be removed, manipulated, and examined histologically. Our investigations have shown that this method is satisfactory and convenient provided techniques are standardized and trauma to the membrane is avoided.

\section{Materials and Methods}

\section{ORGANISMS}

Six species of Candida were investigated: $C$. albicans (28 isolates), C. tropicalis (16), C. pseudotropicalis (4), C. parapsilosis (9), C. krusei (4), and C. guilliermondii (3). One isolate of Torulopsis glabrata and two of Saccharomyces cerevisiae were also included. All 67 isolates were obtained from clinical specimens received in the routine laboratories. Identification was by standard methods. Isolates were maintained on peptone-dextrose agar slants and stored at $4^{\circ} \mathrm{C}$.

PREPARATION AND STANDARDIZATION OF INOCULUM

Suspensions were prepared from organisms cultured on peptone-dextrose agar slants for 16 to 18 hours at $37^{\circ} \mathrm{C}$. The growth was emulsified in sterile distilled water and the suspensions standardized by a haemocytometer count. Viability counts were made using pour plates incubated for 48 hours at $37^{\circ} \mathrm{C}$. 
After trials an inoculum containing 100,000 cells was taken as a suitable standard; this number suspended in $0.1 \mathrm{ml}$ of distilled water was used for all experiments unless otherwise stated. Sterile distilled water, physiological saline, and suspensions of heatand formalin-killed cells were used as control inocula.

\section{INOCULATION AND HARVESTING}

The eggs used were from Rhode Island Red-Light Sussex hybrids. Between 10 and 20 fertile eggs were inoculated with each organism and 10 or more control eggs were used with each infected batch. Incubation was in a Glevum incubator at $37-38^{\circ} \mathrm{C}$ at a relative humidity of $60 \%$.

Eggs were inoculated at 10 days. Viability of the embryos was checked throughout the incubation period by candling. Dead embryos were removed for examination and sterility tests. Viable embryos were harvested and examined at varying intervals. All the surviving eggs were harvested on the eighth or ninth day after inoculation and examined. The inoculation and harvesting techniques were as described by Partridge (1959).

To check contamination, the yolk sac, other fluids and portions of the CAM were inoculated on to peptone-dextrose agar plates, and smears stained and examined.

\section{HISTOPATHOLOGY}

After macroscopic examination, the membrane was fixed flat by pushing its edges into an agar plate which was gently flooded with $10 \%$ formalin. The embryo was also preserved in formalin. Sections of the CAM and embryo were stained by haematoxylin and eosin, periodic-acid-Schiff, and methenamine silver.

\section{Results}

Evidence of infection and virulence of the fungus

\begin{tabular}{|c|c|c|}
\hline Species (no. of isolates) & $\begin{array}{l}\text { Visible Lesions } \\
\text { on CAM }\end{array}$ & Embryo Survival \\
\hline $\begin{array}{l}\text { C. albicans }(28) \\
\text { C. tropicalis }(16)\end{array}$ & $\begin{array}{l}24-48 \mathrm{hr} \\
72 \mathrm{hr}\end{array}$ & $\begin{array}{l}50 \% \text { mortality } 48-72 \mathrm{hr} \\
50 \% \text { mortality } 3-5 \text { days; } \\
\text { virulent strains } 48 \mathrm{hr}\end{array}$ \\
\hline C. pseudotropicalis (4) & $5-6$ days & $\begin{array}{l}\text { No deaths before } 6 \text { th day, } \\
50 \% \text { mortality } 8 \text { days. }\end{array}$ \\
\hline $\begin{array}{l}\text { C. parapsilosis (9) } \\
\text { C. krusei (4) } \\
\text { C. guilliermondii (3) } \\
\text { Torulopsis glabrata (1) } \\
\text { Saccharomyces } \\
\text { cerevisiae (2) }\end{array}$ & $\left.\begin{array}{l}6-7 \text { days } \\
\text { Nil in } 8 \text { days } \\
\text { Nil in } 8 \text { days } \\
\text { Nil in } 8 \text { days } \\
\text { Nil in } 8 \text { days }\end{array}\right\}$ & No deaths in 8 days \\
\hline
\end{tabular}

Table I Infection of the chorioallantoic membrane (CAM) with standard inoculum $(100,000$ cells in $0 \cdot 1$ $m l)$

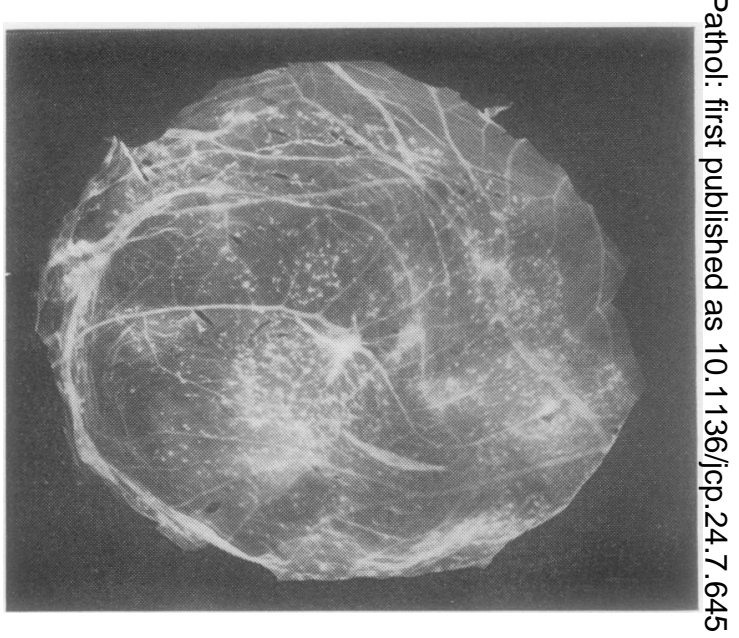

Fig. 1 Candida albicans: infection of the chorioallantoic오 membrane after 48 hours ( $t$ welfth day of embryo development $).(\times 2)$

were determined by inspection of the CAM and the condition of the embryos at harvesting (Table I).

CHORIOALLANTOIC MEMBRANES

Foci of infection were well distributed over the membrane 'floor' of the artificial air space. It was found that counts of lesions on the CAM were noto feasible, since the yeasts proliferated too rapidly and ${ }_{\circ}^{\Phi}$ often developed a tangle of hyphae so that colonies $\vec{\Rightarrow}$ or nodules could not be detected individually. A few3 infected and control eggs suffered slight trauma from? drilling or CAM separation but this was uncommon.

Lesions produced by isolates of the six Candida species were first compared using the standard 0 inoculum $\left(10^{5}\right.$ cells $)$.

\section{C. albicans}

Most isolates produced visible lesions within 24 to 48 hours (Fig. 1). These were greyish and opaque, $?$ ranging from pinpoint to $2 \mathrm{~mm}$ in diameter, and developed cream-coloured centres. Discrete domeshaped nodules of $2 \mathrm{~mm}$ or more diameter were usually visible after 72 to 96 hours.

\section{C. tropicalis}

Lesions usually developed more slowly than withe C. albicans and were less severe. They becameo visible after 48 to 72 hours and attained $2 \mathrm{mmo}$ diameter after 96 hours.

Standard inocula of the other species produced little or no infection within the experimental period: The inoculum was accordingly increased tenfold when $C$. krusei produced lesions after five days and 
C. guilliermondii and Torulopsis glabrata after seven to eight days. Saccharomyces cerevisiae produced lesions in some of the eggs after several days.

The various species could not be differentiated by the macroscopic appearance of the lesions they produced.

\section{CONTROLS}

A few embryos developed small haemorrhages or granular areas due to slight trauma in drilling or CAM separation. Otherwise no lesions were noted.

\section{HISTOPATHOLOGY OF THE MEMBRANES}

The pattern of fungal invasion and reaction of the

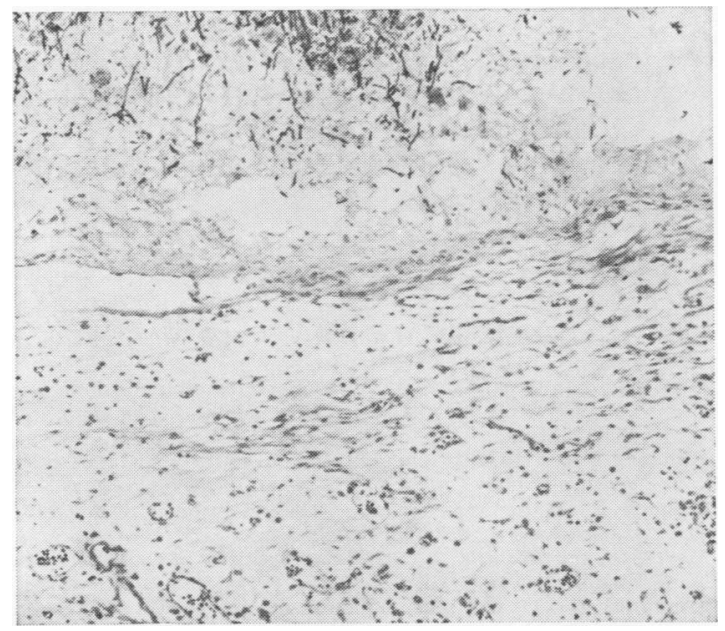

Fig. 2.

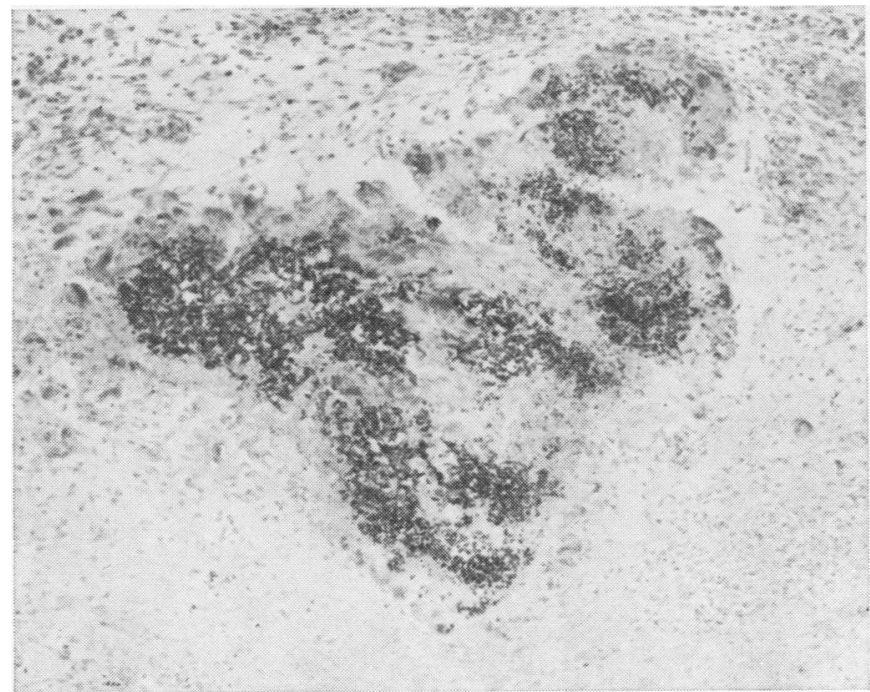

Fig. 2 C. albicans: invasion of ectoderm by yeasts; thickening and increased cellularity of ectoderm and mesoderm (five-day infection; periodic-acid-Schiffl haematoxylin: $\times 100$ ).

Fig. 3 C. albicans: abscess-like area in mesoderm, cellular reaction in tissues and proliferation of Candida within abscess (eight-day infection; periodic-acidSchifflhaematoxylin: $\times 160$ ). membrane tissues was similar for all species, but varied in degree according to the virulence of the rganism.

The first visible reaction was hyperplasia and a loss of architecture and degeneration of rarely any response of the entode flammatory cells in the mesoderm (Fig. 2).

Invasion of the mesoderm by Candida produced a marked reaction of the tissues to localize the organism, sometimes resulting in abscess-like lesions thin the membrane. These were usually found only wen the embryos had survived eight or nine days The degree of mycelial development within the tissues varied according to the species. $C$. albicans generally produced invasive mycelium within 24 hours, $C$. tropicalis more slowly. Most of the other ecies produced mycelium in the tissues, but only

EMBRYOS

Much variation was observed in the effects of the disease on embryo survival. Dead embryos were frequently oedematous, sometimes with haemorages and distended abdomens. Evidence of fungal

The time of death following inoculation was estimated by candling. A further rough guide was

Fig. 3. 
the size of the harvested embryo compared with that of normal controls.

\section{Survival rates}

The daily deaths of embryos were recorded over the post-inoculation period, and the survival rates calculated (Table I).

\section{APPLICATION OF TECHNIQUE}

The technique of CAM inoculation for determining the pathogenicity of an organism was found to be sensitive enough to detect differences in virulence not only between species but between isolates of the same species. This was shown by its use in testing clinical specimens, and comparing the pathogenicity of polyene-sensitive and polyene-resistant Candida isolates in vitro (Athar and Winner, 1971).

Since 1967 we have used the method as a pathogenicity test for clinical and research isolates of candida.

\section{Discussion}

The species we have examined could be separated into three groups according to their pathogenicity. C. albicans and C. tropicalis produced macroscopic membrane lesions and embryo deaths within a few days of inoculation with 100,000 viable yeast cells in $0.1 \mathrm{ml}$ of distilled water. C. pseudotropicalis, $C$. parapsilosis, and $C$. krusei require a tenfold increase in the inoculum concentration for the development of well defined lesions and for lethal infections. C. guilliermondii, Torulopsis glabrata, and Saccharomyces cerevisiae showed little evidence of membrane infection, tissue reaction, or embryo deaths with the large inoculum.

This gradation in pathogenicity of the Candida species is similar to that observed by Stanley and Hurley (1967) after growth in cultures of mouse renal epithelial cells, differing only in the position of $C$. krusei. It confirms their known relative pathogenicities in man. It appears therefore reasonable to assume that differences in the pathogenicity of different isolates of the same species observed by this technique will reflect their relative pathogenicity in man, and that the technique may be used as an assay of human pathogenicity. In another study the same method has also been used to assess the pathogenicity of Candida isolates which were sensitive and resis tant to nystatin and amphotericin B (Athar and Winner, 1971). These results were confirmed by? mouse inoculation.

It is essential for such comparative work that standard inoculum be used, and that trauma of the membrane during manipulation and inoculation be avoided.

Up to the time of writing we have examined over100 isolates of various Candida species by this method, which is now our routine method fotw assessing the pathogenicity of Candida. We find ie to be much more sensitive and less trouble thanes animal inoculation and we recommend it to clinicals pathologists.

We thank Mrs C. Williams and Miss P. Thorne fotr technical assistance, and Miss P. M. Turnbull ang Mr A. Campbell for photography.

This work was supported by a research grant frong E. R. Squibb and Sons, Ltd.

\section{References}

Athar, M. A., and Winner, H. I. (1971). J. Med. Microbiol. (In the press.)

Denny, M. J., and Partridge, B. M. (1968). Tetrazolium medium as a aid in the routine diagnosis of Candida. J. clin. Path., 2 383-386.

Hinshaw, W. R. (1934). Moniliasis (thrush) in turkeys and chickenæ World's Poultry Congress, 5th Rome, Proceedings, 3, 190-19:0

Jungherr, E. (1933). Observations on a severe outbreak of mycosis i chicks. J. agric. Res., 46, 169-178.

Meyer, E., and Ordal, Z. J. (1946). Pathogenicity of Candida specie for the chick embryo. J. Bact., 52, 615-616.

Moore, M. (1941). The chorio-allantoic membrane of the developing chick as a medium for the cultivation and histopathologic study of pathogenic fungi. Amer. J. Path., 17, 103-120.

Norris, R. F., Shorey, W. K., and Bongiovanni, A. M. (1948). Lesions produced in chick embryos by Candida (Monilia) albicans Arch. Path. , 45, 506-512.

Partridge, B. M. (1959). The use of the chorioallantoic membrane of the developing chick embryo for culture of dermatophytes. $P$. invest. Derm., 32, 605-619.

Partridge, B. M. (1965). Studies of pathogenic fungi in the developing chick embryo. PhD thesis, London.

Roessler, W. G., Converse, J. L., and Geating, J. A. (1961). Virulence assay of Coccidioides immitis in embryonated eggs. J. Bact., 81, 226-232.

Salisbury, R. M. (1949). Poultry diseases caused by mould and yeasi infections. N.Z.J. Agric., 79, 558.

Stanley, V. C., and Hurley, R. (1967). Growth of Candida species in cultures of mouse epithelial cells. J. Path. Bact., 94, 301-315

Winner, H. I., and Hurley, R. (1964). Candida albicans. Churchilto London. 